\title{
A EDUCAÇÃO BRASILEIRA NO MOVIMENTO DA HISTÓRIA: CAMINHOS PERCORRIDOS E OS IMPACTOS SOCIAIS ADVINDOS DESTE PERCURSO
}

\author{
Maria Luiza Barbosa Araujo 0000-0002-8654-4863 \\ Ms. Maria Márcia Melo de Castro Martins 0000-0002-8188-9694 \\ Dr. Frederico Jorge Ferreira Costa 0000-0002-8357-4557 \\ Universidade Estadual do Ceará
}

RESUMO: Tece um diálogo sobre a educação brasileira como particularidade integrante da totalidade social, concreta, com amparo em suas determinações históricas. Examina em que medida a educação nacional expressa o sentido onto-histórico desta vertente e discute seus desdobramentos sobre a sociedade brasileira. Este escrito configura uma demanda universitária de ordem teórica, com elementos de pesquisa bibliográfica e documental. Os resultados apontam que a educação brasileira se materializa por diversos caminhos, alguns destes na luta por direitos essenciais às pessoas, a exemplo da conquista de aparatos legais que melhor asseguram a educação, embora como efeito de tensões no âmbito da sociedade capitalista, atendendo, quase sempre, a interesses da classe dominante, a favor do crescimento do capital nacional e internacional. Nesse sentido, foi possivel identificar, no movimento da história, um conjunto de acontecimentos de natureza social, política e econômica determinantes para o desenvolvimento da sociedade pátria, como um todo. Com efeito, considera-se que a educação é componente essencial para a humanização do ser, reprodução da sociedade e emancipação humana, devendo ser cuidada como prioridade social.

PALAVRAS-CHAVE: Educação brasileira; Determinações Históricas; Reprodução Social.

\section{BRAZILIAN EDUCATION IN THE STREAM OF HISTORY:} \section{PATHWAYS AND THE SOCIAL IMPACTS THAT ARISE FROM THIS JOURNEY}

ABSTRACT: This paper establishes a dialogue about Brazilian education as a special feature, a key part of the social entirety and a factual situation tangible and sustained in its historical determinations. This scientific work examines some aspects in relation to the national education and expresses the ontological and historical meaning of this strand as well as discusses its developments on Brazilian society. This writing constitutes an university requirement of theoretical order, with elements of bibliographic and documentary research. The results achieved highlights that Brazilian education materializes in several ways, some of them in the struggle for essential rights to people, such as the conquest of legal support able to ensure education, although as an effect of tensions within the capitalist society which attends almost always to the interests of the ruling class, in favor of the growth of national and international capital. In this sense, it was possible to identify, in the stream of history, a set of events of social, political and economic nature that were crucial for the development of the homeland society as a whole. Indeed, it is considered that education is an essential component for the humanization of being, reproduction of society and human emancipation, and should be taken care of as a social priority. 


\section{Educere "Educare \\ ReVISTA DE EduCAČ̃̃o}

Programa de Pós-Graduação em Educação - Universidade Estadual do Oeste do Paraná

\section{INTRODUÇÃO}

Estudar a educação brasileira é uma tarefa que requer, antes de tudo, compreender a educação, em seu entendimento ontológico, isto é, como mediação para produzir e reproduzir socialmente, tanto em sentido lato como em senso estreito e, com esse fundamento, situá-la como particularidade constituinte de uma totalidade social, histórica e concreta.

Saviani (2007) evoca a ideia de que a educação brasileira é historicamente determinada por uma série de acontecimentos: a chegada da Coroa Portuguesa ao Brasil, em 1500 e, mais tarde, em 1549, a dos Jesuitas, tendo estes explorado e expropriado os povos indígenas material e culturalmente. Segundo Bóris Fausto e Sérgio Fausto (1996), esses acontecimentos decorreram da expansão marítima portuguesa iniciada no século $\mathrm{XV}$, que tinha o objetivo de ocupar e explorar mais espaços. Esta expansão decorre da transição da sociedade feudal para a de cunho capitalista, por meio da generalização das relações mercantis, do acúmulo de riqueza e terras, a qual, consoante Saviani (2013, p. 26), “[...] é dividida em classes com interesses antagônicos”.

Ainda em relação às determinações que constituíram a educação brasileira, destaca-se, o fato de que, na seara legislativa educacional, dos anos de 1960 a 1990, a educação esteve regida por três distintas leis, sendo a última a que lhe assegurou mais direitos - Diretrizes e Bases da Educação Nacional (LDB), n. 9.394 de dezembro de 1996, com amparo na Constituição de 1988.

Em meio a essa trajetória, a educação brasileira foi objeto de influxos importantes do golpe militar de 1964 (SAVIANI, 2007). Após o fim do regime ditatorial, em meados dos anos de 1980, e em decorrência da redemocratização do País, mudanças foram introduzidas, via legislação, a exemplo da referida LDB 9.394/96, no modo de organizar o sistema educacional brasileiro, nos âmbitos da educação básica e do ensino superior.

Depois de quase duas décadas de governos de direita, na liderança brasileira, pós-regime militar, ascendeu à Presidência da República, de 2001 a 


\section{Educere Educare \\ ReVISTA DE EduCAČ̃̃o}

Programa de Pós-Graduação em Educação - Universidade Estadual do Oeste do Paraná

2016, um representante advindo das camadas populares (SAVIANI, 2018). Nesse período, houve expansão da oferta da educação, sobretudo de nível superior, o que se deu, principalmente, via instituições de ensino superior (IES) privadas. A educação passou à categoria de serviços, com o avanço do neoliberalismo e por influência de organismos multilaterais. Os filhos da classe trabalhadora têm a oportunidade de ingressar no ensino superior, ainda que a maior parcela desse público esteja inserida nas IES privadas, com financiamento do Estado (MANCEBO, 2004; SGUISSARDI, 2006).

A classe dominante, entretanto, opressora, jamais aceitou o fato de os estratos populares terem seus direitos assegurados e postos em prática, o que culminou em um golpe dos Poderes Legislativo e Judiciário, em 2016, derrubando o governo popular, elevando à Presidência do Brasil um representante ilegitimo, antipopular e antinacional (SAVIANI, 2018), com desdobramentos importantes para o sistema educacional brasileiro, sinalizando retrocessos e perdas para a educação da classe trabalhadora, a exemplo da Base Nacional Comum Curricular (BNCC), Reforma do Ensino Médio e Projeto Escola Sem Partido.

Ante o exposto, explicitamos que este estudo tem curso na inquietação dos autores em compreender as determinações históricas que marcaram e assinalam a educação brasileira, suas implicações e desdobramentos para a sociedade, mediante alienação e reificação decorrentes da exploração do trabalho na sociedade capitalista.

Ancorando-se na perspectiva materialista histórico-dialética, e na educação em seu sentido ontológico, como prática social, e de seu papel na humanização do ser, reprodução da sociedade e emancipação humana, a investigação ora relatada propõe tecer um diálogo sobre a educação brasileira como particularidade integrante da totalidade social, concreta, com amparo em suas determinações históricas. Demanda examinar em que medida ela expressa o sentido onto-histórico da educação e discutir seus desdobramentos sobre a sociedade pátria. 


\section{Educere Educare \\ ReVISTA DE EduCACÃ̃o}

Programa de Pós-Graduação em Educação - Universidade Estadual do Oeste do Paraná

Esta conforma uma pesquisa de cariz teórico com elementos de busca bibliográfica e documental. Para tanto, apoiamo-nos em produções acadêmicocientíficas, literatura e legislação específicas da área.

\section{EDUCAÇÃO BRASILEIRA: CONTEXTO HISTÓRICO, CAMINHOS TRILHADOS E FRUTOS COLHIDOS NESSA TRAJETÓRIA}

O Brasil pertence a um número de países cuja formação social se estruturou sob a influência de fatores externos. Para o Território brasileiro foram transferidas muitas modalidades de organização econômica, política e social, características do mundo europeu. Segundo Maestri (2019), a colonização territorial portuguesa assentou-se na agricultura escravista, latifundiária, monocultora e exportadora, que praticou trabalho coercitivo, inicialmente das comunidades americanas nativas do litoral, e, após a extinção tendencial destas, em formato crescente, de africanas e africanos escravizados.

Como sinalizado, a educação nacional está inserida no movimento da história do Brasil e, de acordo com Romanelli (1986), não é algo fácil conceituála, sobretudo quando consideramos a complexidade da nossa realidade e os períodos históricos vividos, ao que se acresce o fato de que ela sempre foi marcada por avanços e retrocessos. Por isso, refletir a educação num determinado contexto requer, antes, pensar o próprio contexto, pois a ação educativa sucede de acordo com a compreensão que se tem da realidade social em que está inserida.

Podemos, ainda, acentuar que a ação educativa é inerente à vida humana, pois o fato de os homens possuírem um metabolismo permanente com a natureza, dentro de uma realidade social e concreta, os faz transformar a realidade de acordo com suas necessidades e, na medida que isso ocorre, eles se transformam. Com isso, educam-se e educam uns aos outros, com suporte na interação social. No âmbito dessa ação educativa, compreende-se uma educação, tanto no sentido largo, como no senso estrito (ROMANELLI, 1986). 


\section{Educere "Educare \\ ReVISTA DE EduCAČ̃̃o}

Programa de Pós-Graduação em Educação - Universidade Estadual do Oeste do Paraná

Historicamente, a educação brasileira experimentou muitas imposições, continuidades e descontinuidades, sendo uma ruptura marcante, nessa história, a chegada dos portugueses, em 1500, às terras brasileiras, que, até aquele momento, eram povoadas por indígenas. Com essa vinda inesperada, foram impostos às tribos indígenas costumes de uma cultura estrangeira bem diferente dos habitantes do Brasil, uma vez que viviam e praticavam uma educação de acordo com suas raízes e cultura, ou seja, uma educação na vida e para a vida, posta em prática em uma sociedade sem classes (SAVIANI, 2007).

Saviani (2007) destaca a noção de que essa educação e essa cultura indígenas, além de interrompidas, tomaram novos rumos. Em 1549, chegou ao Brasil a Companhia de Jesus, com a missão de converter os indígenas à religião cristã e submetê-los ao domínio português, por meio da catequese, que os ensinava a ler, escrever e a contar. Em 1599, os Jesuítas reorientam o método de instrução por meio do Ratio Studiorum, documento constituído por 467 regras, com a finalidade de orientar o ensino, buscando uma formação uniforme para quem frequentava os colégios jesuíticos. As atividades oferecidas à nobreza, no entanto, eram direcionadas pelos moldes europeus, ao passo que aos índios era oferecida a catequese. Durante 210 anos, habitaram o Território Brasileiro e, em 1759, foram expulsos por decreto do Marquês de Pombal (Sebastião José de Carvalho e Melo), pois este acusava a companhia de padres de desrespeito, exploração e violação da liberdade dos índios, concorrência desleal, dentre outros pontos, sendo, até este momento, a educação mantida e praticada de acordo com os interesses da Corte Portuguesa.

No século XIX, especificamente em 1822, o Brasil tornou-se independente e uma monarquia escravista. Em 1824, foi promulgada a primeira Constituição do País, por D. Pedro I, a qual assinalou, em um de seus artigos, que o Brasil necessitava de uma legislação específica sobre instrução pública. Em suma, a educação no século XIX expressou aspectos positivos e negativos, sendo afirmativas a institucionalização da escola e a formação de professores, em que esta formação passou a ser ofertada pelas escolas normais, sendo a primeira 


\section{Educere "Educare \\ ReVISTA DE EduCAČ̃̃o}

Programa de Pós-Graduação em Educação - Universidade Estadual do Oeste do Paraná

criada em 1835, em Niterói - RJ, com o intuito de formar professores para atuarem no ensino primário, no entanto, essas escolas funcionavam intermitentemente.

Como aspecto negativo, destaca-se o fato de o Estado não cumprir seu papel como deveria em relação aos investimentos na educação. Por exemplo, os recursos financeiros destinados à educação gravitavam ao redor de $1,99 \%$ do orçamento geral, além da exclusão de escravos, mestiços e brancos pobres do sistema educacional, enquanto os gastos com o serviço militar computavam mais de 20\%. Toda essa realidade de investimento insuficiente e demais descasos relativos à educação repercutem, ainda, nos dias atuais (SAVIANI et al., 2017).

Após extensas reformas educacionais, procedentes desde o século XIX, o século XX privilegiou uma das conquistas mais importantes da educação: a fundação da Associação Brasileira de Educação (ABE), fruto indireto das incipientes industrialização e urbanização, em 1924, sendo esta composta por diversos educadores brasileiros que estavam à frente das lutas em prol da renovação do ensino nacional. É importante frisar que, até o final dos anos de 1920, o ensino brasileiro foi organizado de maneira fragmentária pelas camadas dominantes, que visavam a alimentar e privilegiar os próprios interesses e valores (ROMANELLI, 1986).

Após a Revolução de 30, movimento armado que culminou no golpe de Estado, assumindo a Presidência Getúlio Vargas, foi criado, por pressão dos educadores da ABE, o Ministério da Educação e Saúde. O governo, no entanto, ainda se mantinha alheio aos problemas do ensino e, por tal pretexto, educadores elaboraram o Manifesto dos Pioneiros da Educação Nova, documento que tratava das reformas educacionais no que diz respeito à instrução e a outros aspectos, como a escola única, laicidade, gratuidade, obrigatoriedade, coeducação, descentralização, Universidade, formação docente e democracia.

No ano de 1945, aconteceu, no Brasil, após a derrocada da ditadura do Estado Novo (1937-1945), a eleição presidencial, sendo vencedor Eurico Gaspar 


\section{Educere "Educare \\ ReVISTA DE EduCAČ̃̃o}

Programa de Pós-Graduação em Educação - Universidade Estadual do Oeste do Paraná

Dutra, que então nomeou Clemente Mariani para o Ministério da Educação e Saúde. Mariani deu entrada no processo de elaboração da LDB, concluído em 1961 (LEMME, 2005).

Romanelli (1986) aponta que, dos anos 1920 a 1964, o Brasil vivenciou uma série de revoluções e movimentos armados, que tinham como principal objetivo o rompimento político e econômico com a velha ordem social oligárquica e a implantação definitiva do sistema capitalista no Brasil. A autora acrescenta ainda que, "[...] através desses movimentos e, sobretudo, através da Revolução de 1930, o que se procurou foi um reajustamento constantes dos setores novos da sociedade com o setor tradicional, do ponto de vista interno, e, destes dois com o setor internacional, do ponto de vista externo". (P. 47). Entrementes, o setor político se preocupava com a articulação de golpes para manter seus governantes no poder e, assim, defender seus interesses políticos, no setor econômico. Por exemplo, o País, apesar de ter sofrido com a crise das quedas de exportações cafeeiras, conseguiu se estabelecer, internamente, e progrediu do setor agrícola para o industrial, que necessitou de ampla mão de obra para compor as indústrias. Nesse sentido, viram na educação a possibilidade de adquirir essa mão de obra barata, como evidencia a robusta tendência tecnicista ocorrente na educação, nos anos de 1970.

Promulgada a primeira LDB, Lei 4.024, de dezembro de 1961, inspirada nos princípios da liberdade e solidariedade humana, esta dispôs que a educação deveria ser concedida no lar e na escola, podendo ser transmitida por qualquer pessoa que tivesse um cargo maior na sociedade, como médicos, padres, dentre outros, sendo esse um aspecto negativo, pois se percebe que a profissão docente, mesmo amparada pela lei, não era tratada em sua especificidade, uma vez realizada sem considerar saberes didático-pedagógicos necessários ao magistério, bastando gozar de boa reputação para exercer o ofício docente. A única preocupação era ensinar a instrução básica. Mencionada lei assegurou também entidades públicas e privadas, definindo, ainda, que o Ministério da 


\title{
Educere "Educare \\ ReVISTA DE EduCACÃ̃o
}

Programa de Pós-Graduação em Educação - Universidade Estadual do Oeste do Paraná

Educação e Cultura (MEC) seria o único órgão federal a designar atribuições à educação (OLIVEIRA, 2017).

\begin{abstract}
A Lei de Diretrizes e Bases representou, a nosso ver, um passo adiante no sentido da unificação do sistema escolar e de sua descentralização; porém, [...] ela não pôde escapar às ingerências da luta ideológica e representou, sob aspectos assaz importantes, tais como o da autonomia do Estado, para exercer a função educadora e o da distribuição de recursos para a educação, uma vitória da mentalidade conservadora (ROMANELLI, 1986, p. 187).
\end{abstract}

Tempos depois, no governo de João Goulart, especificamente em março de 1964, Napolitano (2014) relata que militares se uniram e derrubaram o presidente do poder, culminando no golpe que manteve o País durante 20 anos sob um regime ditatorial. Paulo Netto (2016) complementa, ainda, expressando que foram 20 anos longos, em que a sociedade brasileira viveu sob medo, tortura e despolitização.

Durante o regime militar, em 1971, foi alterada a LDB/1961, havendo a promulgação de outra LDB, Lei 5.692, de agosto de 1971. Na concepção de Assis e Medeiros Neta (2015), a LDB de 1971 foi criada em um dos piores momentos que o País vivia, tendo esta o objetivo de reformular o ensino secundário, para torná-lo de cunho profissionalizante, com a finalidade de aprestar mão de obra barata a fim de trabalhar nas fábricas. Importante é salientar que essa proposta educacional era direcionada à classe trabalhadora, pois a elite continuava seus estudos com o objetivo de ingresso no ensino superior. Explicitou-se uma proposta de ensino dual, dotada de interesse de classe, político e econômico.

Somente 21 anos depois, já nos anos de 1980, os militares (1964-1985) deixaram o poder, e, no decurso dos anos de 1980, as bases do Estado Federativo Brasileiro foram se recuperando por meio da democratização (eleições diretas e descentralização fiscal). No final desse decênio, especificamente em 1988, surgiu a Constituição Cidadã, que ampliou e determinou direitos cidadãos (SOUZA; FARIA, 2004).

Nesse novo contexto, as medidas de política educacional vão ser marcadas por uma espécie de neoconservadorismo. Diante do mote do 


\title{
Educere "Educare \\ ReVISTA DE EduCAČ̃̃o
}

Programa de Pós-Graduação em Educação - Universidade Estadual do Oeste do Paraná

\begin{abstract}
"Estado mínimo" passa-se a considerar a chamada "decadência da escola pública" como resultado da incapacidade do Estado de gerir o bem comum. Com isso advoga-se, também no âmbito da educação, a primazia da iniciativa privada regida pelas leis do mercado (SAVIANI, 2018, p. 293).
\end{abstract}

$\mathrm{Na}$ realidade política, em 1989, ocorreram eleições diretas e em 1990 assumiu a Presidência Fernando Collor de Mello, que, no âmbito educacional, se deteve em gerenciar os preços das mensalidades das escolas privadas. Ameaçado de impeachent, em 1992, renunciou ao mandato e foi substituído pelo vicepresidente Itamar Franco. No governo Franco, especificamente em 1993, foi lançado o Plano Decenal: Educação para Todos, sendo foco desse plano o ensino fundamental, uma vez que visava erradicar o analfabetismo e universalizar o ensino fundamental (SAVIANI, 2018).

Já no governo FHC (1995-2001), a promulgação da nova LDB, Lei 9.394, de dezembro de 1996, constituiu passo importante no âmbito da educação brasileira, uma vez que tratou a educação de modo bem mais abrangente. Esta representou, para muitos brasileiros, a esperança de avanços significativos, assegurando, não somente, princípios, mas, também, compromissos e deveres que contribuíssem para o acesso à educação das camadas marginalizadas e excluídas. Se, porém, de um de lado, foi vista como ponte para a luta e conquista de direitos, por outro, foi utilizada como meio de guarda e proteção de direitos privilegiados (SEVERINO, 2018). Ainda para o autor,

\begin{abstract}
A discussão, votação e promulgação da atual LDB se deu num momento específico da história político-econômica do Brasil, marcado por uma tendência, apresentada como inovadora e capaz de trazer a modernidade à educação do país. Assim, no contexto da globalização de todos os setores da vida social, as elites responsáveis pela gestão políticoadministrativa do país rearticulam suas alianças com parceiros estrangeiros, investindo na inserção do Brasil na ordem mundial desenhada pelo modelo neoliberal (p. 61).
\end{abstract}

Ainda no governo FHC, ao final, uma das últimas medidas tomadas foi a entrada, na Câmara dos Deputados, do projeto para o Plano Nacional de Educação (PNE), que consiste em planos e metas para a educação. Em termos 


\section{Educere Educare \\ ReVISTA DE EduCAČ̃̃o}

Programa de Pós-Graduação em Educação - Universidade Estadual do Oeste do Paraná

históricos, o PNE foi mencionado, pela primeira vez, na Constituição de 1934, porém, só surgiu efetivamente em 1962, sendo assegurado pela LDB/1961. Em conformidade com a Constituição de 1988 e com a LDB/1996, foi elaborado o segundo PNE, pela Lei $\mathrm{n}^{\circ} 10.172 / 2001$, o qual esteve em vigência de 2001 a 2011. O terceiro e atual PNE (2014-2024) foi determinado pela Lei $n^{\circ}$ 13.005/2014, sendo válido até 2024 (SAVIANI, 2018).

Em 2001, encerrou-se o governo FHC, e, em 2003, o País passou a ser governado, pela primeira vez, por um representante das camadas populares, Luiz Inácio Lula da Silva, o primeiro presidente do Brasil a olhar para as camadas menosprezadas. Em seu primeiro governo (2003-2006), Lula visava a expandir o acesso à educação para os estratos do povo, por meio de três diretrizes: democratização do acesso e garantia de permanência; qualidade social da educação; regime de colaboração e gestão democrática (LIBÂNEO; OLIVEIRA; TOSCHI, 2017). Ainda nesse governo, criou-se o Fundo de Manutenção e Desenvolvimento da Educação básica (FUNDEB), em substituição ao anterior, sendo fins deste novo conjunto de recursos a sua distribuição pelas escolas do País, levando em consideração o desenvolvimento social e econômico das regiões (BRASIL, 2018).

No período de 2007 a 2010, Lula continuou como presidente do Brasil e prosseguiu com a expansão do ensino por meio de programas educacionais. Em 2011, foi eleita Dilma Rousseff, a primeira mulher presidente do País, fato este de suma importância, visto que as mulheres ainda lutam muito por sua participação efetiva em todos os espaços da sociedade. Dilma deu continuidade às politicas educacionais do governo Lula, encerrando seu primeiro mandato em 2014, com o novo PNE já aprovado para a próxima década. Foi reeleita, porém, em 2016, foi alvo de um golpe, e afastada da Presidência por meio de um impeachment. O trabalho que vinha sendo desenvolvido em relação ao PNE, em parte, previa a incorporação de $10 \%$ do Produto Interno Bruto (PIB) para a educação, algo reivindicado desde 1980; destinação de uma parcela de recursos do pré-sal para a educação; dentre outras providências. Tais intencionalidades 


\section{Educere "Educare \\ ReVISTA DE EduCAČ̃̃o \\ Programa de Pós-Graduação em Educação - Universidade Estadual do Oeste do Paraná}

foram barradas pelo golpe, que elevou à Presidência do País Michel Temer, vicepresidente de Roussef (SAVIANI, 2018).

Retomando as considerações sobre o atual PNE, Dourado e Oliveira (2018) apontam que a aprovação deste novo plano foi algo de enorme relevância, visto que visava à adoção de metas importantes, como a incorporação do percentual de $10 \%$ do PIB para a educação até 2024 e a institucionalização do Sistema Nacional de Educação (SNE), no prazo de dois anos. Com isso, este plano sinalizava para a sociedade brasileira uma nova fase no âmbito das políticas educacionais, no entanto, a realidade foi bem diferente do esperado.

Nesta perspectiva, Saviani (2018) evidencia que várias metas do plano já se venceram sem serem atingidas, e as demais, que ainda não foram cumpridas, ficam inviabilizadas pela Emenda Constitucional que o governo Temer aprovou, limitando por 20 anos os gastos públicos.

Dentre outros projetos educacionais engendrados por Michel Temer, destacam-se: a Base Nacional Comum Curricular do Ensino Fundamental (BNCC), já homologada, e a do Ensino Médio, já elaborada, que em seu governo se reconfigurou por meio da Reforma do Ensino Médio e do Projeto Escola sem Partido (LIBÂNEO; OLIVEIRA; TOSCHI, 2017).

No âmbito dos projetos educacionais ora citados, cabe-nos uma explicitação sobre o que os constitui. Começando pela BNCC, no Brasil, desde os anos de 1980/90, já se pronunciava o discurso pela existência de uma base nacional curricular comum. Com a publicação da LDB/1996, sendo a última alteração desta realizada pela Lei 13.415 de 2017, ela exige, em seu Art. 26, que os currículos da educação infantil, do ensino fundamental e do ensino médio devem ter uma base nacional comum, a ser complementada, em cada sistema de ensino e em todo estabelecimento escolar, por uma parte diversificada, de acordo com as características regionais, locais, culturais e econômicas do educando (TRICHES; ARANDA, 2018).

Outra exigência para a implementação da BNCC foi feita pelo PNE (20142024), que estabeleceu, como uma das estratégias da meta 7 , o 


\section{Educere "Educare \\ ReVISTA DE EduCAČ̃̃o}

Programa de Pós-Graduação em Educação - Universidade Estadual do Oeste do Paraná

encaminhamento da BNCC, até junho de 2016. Com efeito, para a elaboração da BNCC, em 2013, a Secretaria de Educação Básica do Ministério da Educação (SEB) convocou uma Comissão de Especialistas oriundos das universidades e institutos federais de ciência e tecnologia, como também aqueles indicados pelo Conselho Nacional de Educação (CONSED) e pela União dos Dirigentes Municipais da Educação (UNDIME). Nesse período, as discussões sobre a BNCC ocuparam espaços importantes no governo Dilma, e com isso começou sua discussão e elaboração pelas pessoas indicadas. Em setembro de 2015, um documento preliminar da base foi submetido a consulta pública, via eletrônica, e, de acordo com a $\mathrm{SEB}$, a sociedade teria até dezembro do mesmo ano para enviar as propostas das escolas, movimentos sociais e entidades públicas e privadas ao MEC. Após isso, as propostas seriam analisadas pelos especialistas, podendo ser estas postas no documento inicial (AGUIAR, 2018).

Vale salientar que a proposta da BNCC também foi analisada por leitores que a receberam de modo crítico. A Associação Nacional de Pós-Graduação e Pesquisa em Educação (ANPED), por exemplo, teceu críticas ao documento, esclarecendo que ele não estava levando em consideração a diversidade do projeto de Nação democrática, provocando ainda uma descaracterização do estudante, desconsiderando a complexidade do trabalho na escola, convertendo o direito de aprender a uma lista de conteúdos, dentre outras opiniões contrárias. Em meio a tantas considerações, o MEC reformulou o documento da BNCC e ofereceu a segunda versão no dia 3 de maio de 2016. Não era, no entanto, a entrega da segunda proposta da base, mas sim de uma nova instauração para o processo de elaboração da base, que, então, seria conduzida pelo CONSED e UNDIME, que iriam promover seminários de discussão até junho do ano seguinte. Vale ressaltar que, naquele momento, o panorama político estava turbulento, sendo a situação agravada, pois Michel Temer, logo que assumiu a Presidência, engendrou, no panorama educacional, várias mudanças, sendo uma delas o lançamento da Medida Provisória n. 746/2016, de 22 de setembro de 2016 (AGUIAR, 2018). 


\section{Educere "Educare \\ ReVISTA DE EduCAČ̃̃o}

Programa de Pós-Graduação em Educação - Universidade Estadual do Oeste do Paraná

No dia 3 de junho de 2016, o MEC adiou a entrega da versão final da BNCC para novembro do mesmo ano, indo, assim, de encontro ao que havia sido estabelecido pelo PNE. Na segunda versão, as críticas ainda se mantiveram, pois os problemas apontados na primeira proposta não haviam sido sanados na nova propositura. Finalmente, a terceira versão do documento foi entregue ao $\mathrm{CNE}$, pelo Ministro da Educação, Mendonça Filho, em fevereiro de 2017, sendo esta aplaudida pelos que faziam parte do Movimento pela Base Nacional Comum, como, por exemplo, o coordenador da Fundação Lemann, que declarou ser a base um mecanismo de aprendizagem mais ativa, prática e menos expositiva. Contrária às ideias dos que apoiaram esta versão, a ANPED, Associação Nacional Pela Formação dos Profissionais da Educação (ANFOPE) e a Associação Brasileira de Currículo $(\mathrm{ABdC})$ se posicionaram criticamente, explicitando que o documento exprimia equívocos, omissões e retrocessos, não respeitando o pluralismo de ideias, sendo conteudista, disciplinarista etc (AGUIAR, 2018).

A BNCC que diz respeito à educação infantil e ao ensino fundamental já se encontra aprovada, e a do ensino médio, embora ainda não tenha sido publicada em sua versão final, está elaborada. Com isso, ante o contexto histórico de elaboração da BNCC expresso acima, pode-se perceber que a educação "[...] está inserida em um contexto de interesses econômicos e políticos e que as políticas educativas estão sendo pensadas e gestadas por grupos de viés neoliberal, já que se constata cada vez mais a presença do setor privado mercantil definindo a educação pública" (TRICHES; ARANDA, 2018, p. 13).

Algo também bastante grave na referida BNCC diz respeito à padronização de currículo que propõe. Neste sentido, Santos e Diniz-Pereira (2016, p. 288) esclarecem que "[...] a proposta de uma BNCC termina sendo uma medida inócua, pois a experiência tem mostrado que os professores, com raras exceções, não consultam os documentos oficiais para preparar suas aulas [...]”. Desse modo, são necessárias outras propostas para elevar a qualidade de ensino, como melhoria da formação docente, das condições de trabalho dos professores e dos espaços escolares como um todo, pois somente docentes bem qualificados 


\section{Educere "Educare \\ ReVISTA DE EduCAČ̃̃o}

Programa de Pós-Graduação em Educação - Universidade Estadual do Oeste do Paraná

podem contribuir para democratizar a educação (SANTOS; DINIZ-PEREIRA, 2016).

Cuidando-se, agora, do ensino médio e das reformas que o permeiam, esse nível de ensino é caracterizado, de acordo com a LDB de 1996, como a última etapa da educação básica, com duração de três anos, tendo por finalidade a consolidação e o aprofundamento de conhecimentos adquiridos no ensino fundamental; é preparação para o trabalho e cidadania; formação ética, autonomia intelectual e pensamento crítico; e compreensão dos fundamentos científico-tecnológicos, de modo que o aluno possa relacionar teoria e prática no âmbito das disciplinas (BRASIL, 2017).

Tendo a LDB/1996 definido o ensino médio e suas finalidades, em 1998, foi promulgada, pelo $\mathrm{CNE}$, a Resolução $\mathrm{CNE} / \mathrm{CEB}$ 03, que estabeleceu as Diretrizes Curriculares Nacionais para o Ensino Médio. Os argumentos para tal reforma curricular, nesse momento, estavam expressos na pretensão de que a escola atendesse à demanda das transformações nos processos de produção de mercadorias e serviços, bem como o uso das tecnologias e gestão do trabalho. Em 2012 foram publicadas novas diretrizes para o ensino médio, por meio da Resolução CNE/CEB 02, orientadas por uma das políticas do governo Lula, que tratou do Ensino Médio Integrado (EMS) à Formação Profissional, pois tal política focava o trabalho como meio formativo. As novas diretrizes assentavamse no princípio da formação integral do aluno, nos âmbitos do trabalho, ciência, tecnologia e cultura. Neste sentido, ambas as diretrizes tiveram por finalidade normatizar a organização curricular do ensino médio, porém com vieses diferentes. Após o ano de 2012, foi criada a Comissão Especial destinada a promover Estudos e Proposições para a Reformulação do Ensino Médio (CEENSI), da qual resultou o Projeto de Lei 6.840/2013 e, posteriormente, a Medida Provisória 746/16, que foi base para a criação da Lei 13.415/2017, a qual orienta a reforma do ensino médio (SILVA; SCHEIBE, 2017).

Em relação ao Projeto de Lei 6.840/2013: “[...] constam duas propostas principais, a de organização curricular com base em ênfases/áreas de escolhas 


\section{Educere "Educare \\ ReVISTA DE EduCAČ̃̃o}

Programa de Pós-Graduação em Educação - Universidade Estadual do Oeste do Paraná

por parte dos estudantes e também a progressiva obrigatoriedade de jornada escolar com o mínimo de sete horas diárias para todos" (SILVA; SCHEIBE, 2017, p. 25). Ainda de acordo com Silva e Scheibe (2017), a escolha, por parte dos alunos, do que pretendem estudar remonta a um modelo utilizado durante o regime militar, que reforça a fragmentação dos conhecimentos, negando ao escolar um conjunto de conhecimentos. A jornada escolar de sete horas desconsidera a ideia de muitos alunos terem que, além de estudar, trabalhar, e também o fato de muitas escolas não disporem de estrutura física adequada para suportar o ensino integral, havendo ainda uma quantidade insuficiente de professores. Essas propostas e outras do projeto levaram à manifestação do Movimento Nacional em Defesa do Ensino Médio, composto por algumas entidades do espaço educacional, como a ANFOPE e a ANPED, dentre outras, sendo este movimento criado em 2014. Em decorrência dos manifestos contrários ao projeto, este foi objeto de algumas modificações. Em 2015, estava previsto que o projeto fosse a plenário, porém, nos anos de 2015 e 2016, não foi contemplado nas discussões realizadas no Congresso, pois o foco estava direcionado para a política do País, ou seja, o impeachment da presidenta Dilma. Com efeito, após Michel Temer assumir a Presidência, logo encaminhou para o Congresso Nacional a Medida Provisória n. 746, de 22 de setembro de 2016.

Após isso, o Movimento Nacional em Defesa do Ensino Médio se manifestou por via da participação em audiências públicas, e como ato de maior manifestação e resistência "[...] é preciso dar o devido destaque às ocupações de mais de 1.200 escolas, Institutos Federais e Universidades por estudantes de todo o país" (SILVA; SCHEIBE, 2017, p. 26). No âmbito das propostas da Medida Provisória, as de maiores repercussões foram: organização das cinco áreas diversificadas do ensino médio, de escolha do aluno; instituição do sistema de créditos similar ao do regime militar, criado em 1969, na reforma do ensino superior; aproveitamento dos conteúdos no ensino superior, cursados no ensino médio; supressão do ensino de artes, Sociologia, Filosofia e Educação Física. Fator preocupante também é a valorização do notório saber expressa na Reforma 


\section{Educere Educare \\ ReVISTA DE EduCACÃ̃o}

Programa de Pós-Graduação em Educação - Universidade Estadual do Oeste do Paraná

do Ensino Médio, algo reivindicado, historicamente, desde 1932 pelos "pioneiros da educação nova", que eram contra esse tipo de saber (PEREIRA; TEIXEIRA, 2018). Em relação ao notório saber, Silva e Scheibe (2017) esclarecem que, mesmo que os profissionais de outras áreas (que não sejam da licenciatura) sejam direcionados para o ensino na modalidade de ensino técnico e profissional, essa situação institui a precarização e a desvalorização da docência, pois a formação acadêmica desses profissionais não é voltada para a licenciatura.

A Medida Provisória (MP) tramitou no Congresso Nacional de outubro de 2016 a fevereiro de 2017, e foi discutida em 11 audiências públicas, em que um dos argumentos de defesa era a necessidade de adequar a formação dos estudantes de ensino médio ao mercado de trabalho (SILVA; SCHEIBE, 2017). Em relação a este argumento de defesa, esclarece Kuenzer (2017, p. 341 - 342):

Em resumo, o ensino médio, na atual versão, integra a pedagogia da acumulação flexível e tem como finalidade a formação de trabalhadores com subjetividades flexiveis, por meio de uma base de educação geral complementada por itinerários formativos por área de conhecimento, incluindo a educação técnica e profissional; a formação profissional é disponibilizada de forma diferenciada por origem de classe, de modo a levar os que vivem do trabalho a exercer, e aceitar, de forma natural, as múltiplas tarefas no mercado flexibilizado. Ser multitarefa, neste caso, implica exercer trabalhos disponibilizados pelo mercado, para os quais seja suficiente um rápido treinamento, a partir de algum aporte de educação geral, seja no nível básico, técnico ou superior. Para alguns, significará exercer trabalhos qualificados e criativos; esses não serão atingidos pela reforma do ensino médio porque dispõem, em face de sua origem de classe, de outros espaços de formação, que não a escola pública. Para a maioria dos trabalhadores, contudo, ser multitarefa significará exercer trabalhos temporários simplificados, repetitivos e fragmentados, que não necessitam de formação qualificada, mas provavelmente de certificados ou reconhecimento de competências, o que o atual ensino médio talvez atenda.

Neste sentido, a MP foi aprovada pelo Congresso e logo se efetivou na Lei 13.415/2017, que fez mudanças na LDB/1996, em relação à carga horária obrigatória na educação básica. No ensino médio, por exemplo, será aumentada, progressivamente, para 1.400 horas; realização de parcerias público-privadas 


\section{Educere "Educare \\ ReVISTA DE EduCAČ̃̃o}

Programa de Pós-Graduação em Educação - Universidade Estadual do Oeste do Paraná

para o financiamento da educação, sendo esta alteração relacionada ao FUNDEB, dentre outras (SILVA; SCHEIBE, 2017).

Dos projetos educacionais citados, por fim, temos o Projeto Escola sem Partido, que nasceu em 2004, sendo apresentado, primeiramente, no Rio de Janeiro, pelo deputado Flávio Bolsonaro. A segunda vez, em um município daquele Estado, pelo vereador Carlos Bolsonaro, ambos filhos de Jair Bolsonaro. O projeto foi se espalhando pelo País, sendo apresentado, em âmbito nacional, na Câmara dos Deputados pelo parlamentar Izalci Lucas Ferreira, na forma de Projeto de Lei (PL) 867/2015, em que este visa a modificar a LDB/1996, implementando suas ideias às diretrizes e bases (MANHAS, 2016).

O Projeto Escola sem Partido defende a neutralidade política, ideológica e religiosa do Estado; em sala de aula, a prática de qualquer doutrinação política e ideológica, seja por meio da fala de professores, alunos, ou até mesmo pelas atividades propostas, não é permitida; o professor não poderá se posicionar politicamente ou de acordo com suas crenças, ou seja, deverá ser um sujeito neutro em todos os assuntos (BRASIL, 2015). Releva frisar que o projeto é inspirado em iniciativas internacionais e visa a chegar a três objetivos: "[...] a “descontaminação e 'desmonopolização' política e ideológica das escolas”; o "respeito à integridade intelectual e moral dos estudantes"; e o "respeito ao direito dos pais de dar aos seus filhos uma educação moral que esteja de acordo com suas próprias convicções” (CARA, 2016, p. 45).

Nesse sentido, a luta pela superação dessa condição de profunda alienação e reificação da sociedade exige, no limite, a superação do trabalho explorado, e, portanto, da sociedade de classes. Com isso, reiteramos a função social da educação como mediadora, feita ato político, na emancipação humana. 


\section{Educere "Educare \\ RevisTA De EduCAC̄̃̃o \\ Programa de Pós-Graduação em Educação - Universidade Estadual do Oeste do Paraná}

\section{CONSIDERAÇÕES FINAIS}

Ante o exposto, podemos perceber que a educação brasileira, no evolver de sua história, até os dias atuais, trilhou muitos caminhos e enfrentou diversos impasses na luta por direitos que são essenciais a toda a sociedade. Tudo isso contribuiu e concorre, positiva ou negativamente, para o desenvolvimento da sociedade brasileira como um todo.

No âmbito dessas contribuições, consideramos positivas todas as lutas realizadas em prol da conquista e garantia de leis (como por exemplo, LDB, PNE etc.) e outros meios que assegurem e ampliem o acesso à educação de qualidade. Dentre os pontos negativos que envolvem a educação, destacamos: o fato de a educação brasileira, desde muito tempo, não ser tratada como prioridade social, sendo ofertada, ainda, como meio para a busca de privilégios e fortalecimento do sistema capitalista; leis e projetos que retrocedem nossas lutas e arrancam nossos direitos (como, por exemplo, Lei da Reforma do Ensino Médio, Projeto Escola sem Partido etc.).

Neste sentido, ante toda essa trajetória experimentada pela educação brasileira, consideramos que esta é componente essencial para humanizar o ser, reprodução da sociedade e emancipação humana, devendo ser tratada como prioridade social. Consideramos, ainda, imprescindiveis as lutas realizadas pelos que acreditam ser a educação uma mediação fundamental no processo de transformação da sociedade. Constituem lutas que, em nosso entendimento, precisam ser permanentes, visto que são constantes os movimentos de ataque à educação.

\section{REFERÊNCIAS}

AGUIAR, M. A. S. Vinte anos da LDB: da Base Nacional Comum à Base Nacional Comum Curricular. In: BRZEZINSKI, I. LDB 1996 vinte anos depois: projetos educacionais em disputa. São Paulo: Cortez, 2018. cap. 3, p. 71-93.

DOURADO, L. F.; OLIVEIRA, J. F. de. BASE NACIONAL COMUM CURRICULAR (BNCC) E OS IMPACTOS NAS POLÍTICAS DE REGULAÇÃO E AVALIAÇÃO DA 


\section{Educere Educare \\ RevISTA DE EdUCACÃ̃o}

Programa de Pós-Graduação em Educação - Universidade Estadual do Oeste do Paraná

EDUCAÇÃO SUPERIOR. In: AGUIAR, M. A. da S.; DOURADO, L. F. A BNCC na contramão do PNE 2014-2024: avaliação e perspectivas. Recife: ANPAE, 2018. cap. V, p. 38-43.

ASSIS, S. M. de; MEDEIROS NETA, O. M. de. Educação profissional no Brasil (1960-2010): uma história entre avanços e recuos. Revista Tópicos

Educacionais. Recife, v. 21, n. 2, p. 190-212, 2015.

BRASIL. PROJETO DE LEI N.` 867 DE 2015. Brasília - DF, 2015. Disponível em: https://bit.ly/1FxS810. Acesso em: 04 out. 2018.

LDB: Lei de diretrizes e bases da educação nacional. Brasília: Senado Federal, Coordenação de Edições Técnicas, 2017. Disponível em: https://bit.ly/2JgDD4H. Acesso em: 04 out. 2018.

Ministério da Educação. Fundeb - Apresentação. Brasília, 2018.

Disponível em: https://bit.ly/2k5HZV2. Acesso em: 10 out. 2018.

CARA, D. O PROGRAMA "ESCOLA SEM PARTIDO" QUER UMA ESCOLA SEM EDUCAÇÃO. In: A ideologia do movimento Escola Sem Partido: 20 autores desmontam o discurso / Ação Educativa Assessoria, Pesquisa e Informação (Org.). — São Paulo: Ação Educativa, 2016. cap. 5, p. 43-47.

FAUSTO, B.; FAUSTO, S. História do Brasil. São Paulo: Edusp, 1996.

IANNI, O. O colapso do populismo no Brasil. 2. ed. Rio de Janeiro, Civilização Brasileira, 1971.

KUENZER, A. Z. Trabalho e escola: a flexibilização do ensino médio no contexto do regime de acumulação flexivel. Educ. Soc. Campinas, v. 38, n. 139, p. 331$354,2017$.

LEMME, P. O Manifesto dos Pioneiros da Educação Nova e suas repercussões na realidade educacional brasileira. Revista Brasileira de Estudos Pedagógicos. Brasília, v. 86, n. 212, p. 163-178, 2005.

LIBÂNEO, J. C.; OLIVEIRA, J. F. de; TOSCHI, M. S. Educação escolar: políticas, estrutura e organização. São Paulo: Cortez Editora, 2017.

MAESTRI, Mário. Revolução e contra-revolução no Brasil 1530-2018. Porto Alegre: FCM, 2018.

MANCEBO, D. Reforma universitária: reflexões sobre a privatização e a mercantilização do conhecimento. Educação e Sociedade. Campinas, v. 25, n. 88, p. 845-866, 2004.

MANHAS, C. Nada mais ideológico que "escola sem partido". In: A ideologia do movimento Escola Sem Partido: 20 autores desmontam o discurso / Ação 


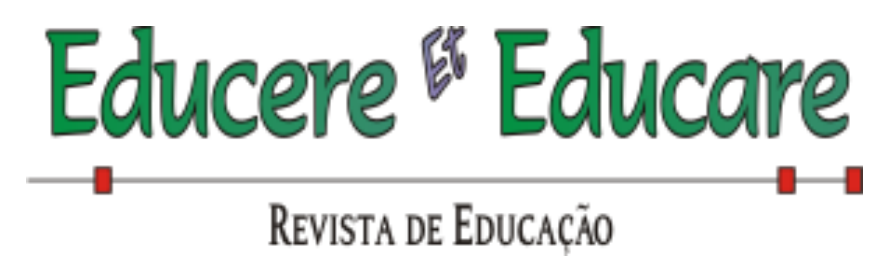

Programa de Pós-Graduação em Educação - Universidade Estadual do Oeste do Paraná

Educativa Assessoria, Pesquisa e Informação (Org.). — São Paulo: Ação Educativa, 2016. cap. 2, p. 15-21.

NAPOLITANO, M. 1964: história do regime militar brasileiro. São Paulo: Editora Contexto, 2014.

NETTO, J. P. Pequena história da ditadura brasileira (1964-1985). São Paulo: Cortez Editora, 2016.

OLIVEIRA, P. V. P de. Manifestos e Leis de Diretrizes e Bases: a Construção de uma Identidade Político-educacional. ANTHESIS. Acre, v. 5, n. 9, p. 208-225, 2017.

PEREIRA, E. W.; TEIXEIRA, Z. A. A LDB e os Novos Contornos da Educação básica. In: BRZEZINSKI, I. LDB 1996 vinte anos depois: projetos educacionais em disputa. São Paulo: Cortez, 2018. cap. 7, p. 181-205.

ROMANELLI, O. de O. História da Educação no Brasil. 8. ed. Petropólis, RJ: Vozes, 1986.

SANTOS, L. L. de C. P.; DINIZ-PEREIRA, J. E. Tentativas de Padronização do Currículo e da Formação de Professores no Brasil. Cad. Cedes. Campinas, v. 36, n. 100, p. 281-300, 2016.

SAVIANI, D. História das ideias pedagógicas no Brasil. São Paulo: Autores Associados, 2007.

Política educacional no Brasil após a Ditadura Militar. Revista HISTEDBR On-line. Campinas, v. 18, n. 2, p. 291-304, 2018.

SEVERINO, A. J. Por uma Aproximação Filosófica da LDB/1996: a difícil construção da cidadania. In: BRZEZINSKI, I. LDB 1996 vinte anos depois: projetos educacionais em disputa. São Paulo: Cortez, 2018. cap. 2, p. 47-69.

SGUISSARDI, V. Reforma universitária no Brasil-1995-2006: precária trajetória e incerto futuro. Educação \& Sociedade. Campinas, v. 27, n. 96, p. 1021-1056, 2006.

SILVA, M. R. da; SCHEIBE, L. Reforma do ensino médio: Pragmatismo e lógica mercantil. Retratos da Escola. Brasília, v. 11, n. 20, p. 19-31, 2017.

SOUZA, D. B. de; FARIA, L. C. M. de. Reforma do Estado, descentralização e municipalização do ensino no Brasil: a gestão politica dos sistemas públicos de ensinopós-LDB 9.394/96. Revista Ensaio. Rio de Janeiro, v. 12, n. 45, p. 925944, 2004.

TRICHES, E. F.;ARANDA, M. A. de M. O PERCURSO DE FORMULAÇÃO DA BASE NACIONAL COMUM CURRICULAR (BNCC). In: SEMINÁRIO FORMAÇÃO DOCENTE: INTERSECÇÃO ENTRE UNIVERSIDADE E ESCOLA, 3., v. 2, n. 2, 


\section{Educere "Educare \\ ReVISTA de EduCAC̄̃o}

Programa de Pós-Graduação em Educação - Universidade Estadual do Oeste do Paraná

2018, Dourados, MS. Anais...Dourados, SP: GEPPEF, 2018. Disponivel em: https://bit.ly/2k76ykr. Acesso em: 02 out. 2018.

Recebido em 15-10-2021

Aceito em 04-11-2021 